\title{
PONTOS DE VISTA SOBRE A FLORESTA AMAZÔNICA: XAMANISMO E TRADUÇÃ O*
}

\author{
Manuela Carneiro da Cunha
}

Foi uma grande e assustadora honra que me fez a Association pour la Recherche en Anthropologie Sociale ao convidar-me a ministrar hoje esta conferência que celebra Robert Hertz. Há exatamente noventa anos, Hertz publicava seu ensaio sobre a morte. Um ensaio que sobreviveu a ele e lhe conferiu essa forma de imortalidade relativa que pode ser a nossa (Vernant 1982), aquela assegurada pela memória das gerações de antropólogos que Ihe sucederam. Eu mesma devo, em grande parte, a esse ensaio a inspiração de meu primeiro livro, que tratava de uma sociedade amazônica - coincidência que faz desta homenagem um exame de consciência, e é nesse sentido que devem ser tomadas as observações que se seguem.

"A sociedade, escrevia Hertz, vê na perda de seus membros...". Algo nos choca nessa frase, nessa maneira tão durkheimiana de elevar a Sociedade ao status de Sujeito. Está fora de moda, e no entanto que boa época aquela em que podíamos, nós, antropólogos, e o ocidente em geral, postular a existência de uma totalização dada a priori. Se tudo isso está morto e enterrado uma primeira vez, as duplas exéquias que assinalam uma renovação ainda não tiveram lugar no entanto, e alguns ainda se debatem em um luto interminável que não mais permite falar antropologia.

Aquilo a que se chamava "cultura" e cujo sujeito era "a Sociedade" se dissolveu. Devemos entender que não existe sistema algum exceto aquele que o antropólogo ingênuo projeta? Anne-Christine Taylor (1995), em uma análise muito sutil e fecunda em que desenvolve idéias de M aurice Bloch (1992), entre outros, ressaltou a existência de teorias implícitas compartilhadas, fundadas sobre uma circularidade de premissas e de práticas que, sem jamais serem expressas em um discurso (a não ser no do 
antropólogo), na medida em que fazem referência umas às outras, se tornam de algum modo "evidentes". A construção dessas sinapses, dessas relações de evidência e de reforço recíproco, produziria, na sociedade, essa síntese particular que é uma cultura. Contudo - e A nne-Christine Taylor (1995:213, nota 4) põe o dedo na questão - , que garantia existe de que essas relações se integrem e de que haja coerência relativa entre pontos de vista separados? Tentarei mostrar que essa preocupação não é apenas antropológica, mas inerente a todos os problemas de tradução, onde quer que se coloquem.

Gostaria de abordar aqui esses temas a partir de um fenômeno que, embora antigo, ainda se nos afigura como um paradoxo.

Observou-se muitas vezes o extraordinário florescimento do xamanismo em situações de dominação de tipo colonial, ou mais exatamente quando povos são capturados nas engrenagens do sistema mundial. No M éxico (Gruzinski 1988), entre os Tupinambá (Vainfas 1995), no Vaupés (Wright e Hill 1992; Hugh-J ones 1996) e em todo o ocidente amazônico, para restringir-me a alguns exemplos da América Latina, o crescimento do xamanismo parece ter coincidido com o enfraquecimento ou o desmoronamento das instituições políticas e econômicas de tipo dito tradicional. Observou-se, também, que esse florescimento não atingiu apenas os povos submetidos: a clientela dos xamãs é, na maior parte dos casos, regional, quando não ainda mais ampla, sem distinção de origem étnica, e isso desde o início da colonização (Gruzinski 1988). Desde o fim do século XVI, no Brasil, a Inquisição perseguia os colonos - alguns, aliás, personagens importantes - que seguiam os profetas indígenas das chamadas "santidades" (Vainfas 1995). Em nossos dias, um outro exemplo estaria nos grupos urbanos de tipo New Age. O crescimento do xamanismo pode se manifestar, assim, no interior de certos grupos indígenas, em movimentos milenaristas, mas também no meio urbano, na mai oria das vezes - e esta é minha terceira observação - com técnicas heteróclitas que se autoproclamam tradicionais.

De maneiras diversas, já se relacionaram formas de organização social, particularmente formas de organização política, e formas de percepção do mundo. Turner (1988), por exemplo, apoiando-se nas teses algo diferentes de Auerbach, distinguiu formas de consciência histórica que correspondem, respectivamente, a organizações políticas autônomas (como a pólis grega) e a conjuntos políticos mais complexos (como os hebreus e as sociedades andinas) que supõem dominação e subordinação. $M$ as as formas concretas que essas estruturas assumem, quer sejam de dominação ou não, permitem perceber, quando consideradas um pou- 
co mais de perto, o modo como tais correspondências se expressam. Tomemos o caso da estrutura em rede, ou mais precisamente fractal (no sentido dado pelos engenheiros, que é um pouco mais amplo que aquele dos matemáticos). De que se trata? De uma organização social e política em que cada unidade é semelhante às unidades que a englobam. Dito de outro modo, uma organização tal que, do macropolítico ao micropolítico, a mesma forma se repita: haverá sempre unidades do mesmo tipo, qualquer que seja a escala em que se as considere. É este o caso, por exemplo, das estruturas segmentares Nuer descritas por Evans-Pritchard. É igualmente o caso, do outro lado do mundo, das estruturas por meio das quais Renard-Casevitz (1993) descreveu, em um artigo notável, os Aruaque subandinos do período colonial. Comunidades autônomas e morfologicamente equivalentes podem se agrupar em unidades mais amplas, cuja forma no entanto compartilham. Da família extensa à unidade local, desta à unidade regional, geral mente definida pelo rio ou por um segmento do rio, da unidade regional à província, desta à etnia e à "nação", cada uma dessas unidades se reveste da mesma forma. Tanto assim que o espaço reflete esse estado de coisas pela reiteração dos topônimos, e a cartografia se repete por todo o vasto território dos Aruaque subandinos.

Dois lugares, no entanto, fazem exceção nessa cartografia fractal: o Pongo Maenike, "ponto culminante do xamanismo [...] [e] ponto de encontro de 'viagens' oníricas ou narcóticas", escreve Renard-Casevitz (1993:27), e o Cerro de la Sal, fonte do sal utilizado, simultaneamente, como gênero alimentício e como moeda. Um comércio historicamente muito ativo, fundado sobre o monopólio do Cerro de la Sal pelos Aruaque, explica seu estatuto de lugar especial, ponto de convergência econômico e político. No interior da rede comercial, à exceção dos Piro, predomina a paz; no exterior, sobretudo contra os Pano do interflúvio, prevalece a guerra, ou melhor, ataques sazonais. O comércio está baseado em parcerias ao longo de toda a rede, e a guerra permite mobilizar de improviso de três a cinco mil homens armados em uma coligação que não repousa em nenhuma hierarquia política (Renard-Casevitz 1992; 1993).

$\mathrm{Na}$ segunda metade do século XIX, os componentes desse sistema desabam um após o outro. Primeiro, a partir dos anos 1860, é a chegada do comércio branco no Marañon e a seguir no Ucayali: os Pano ribeirinhos, parceiros fundamentais dos Aruaque, abandonam o circuito do sal e ligam-se às novas redes comerciais. Tem início, em seguida, a era do caucho, e os A ruaque perdem o controle das jazidas de ferro. Finalmente, na virada do século, o Estado peruano apodera-se do Cerro de la Sal, após uma resistência incitada por um daqueles numerosos messias que 
povoam a história Ashaninka: resistência armada e, por pouco tempo, eficaz, que derrotou a Peruvian Company, companhia inglesa que tinha obtido a concessão do sal. Rompe-se a paz entre todos os parceiros comerciais, os A ruaque e os Pano ribeirinhos inclusive; os "Campa" encontramse presos na engrenagem do caucho, seja como caçadores de índios, Campa ou não, seja diretamente como escravos (Renard-Casevitz 1992:206-208). No alto J uruá, aqueles que até recentemente eram chamados Campa na região, participam, ao lado dos "patrões", do combate contra os Pano locais: Kaxinawá, Yaminahua, Poyanaua e o conjunto compósito conhecido pelo nome de Katukina (Erikson 1993).

O novo sistema, observe-se, também é de tipo fractal. Pois é esta a própria essência da rede de crédito e de produção de caucho. Tomemos o exemplo do J uruá, que tem a vantagem de fornecer uma imagem espacial da rede. Rio mais tortuoso do mundo, com mais meandros do que o M ississipi, o J uruá é um caso extremo, no sentido de que, nesta bacia, ao contrário, por exemplo, da do Purus, o comércio se fazia unicamente por via fluvial. Aqui, o sistema desposava a própria geografia: os negociantes ingleses adiantavam as mercadorias para os negociantes de Belém, que as repassavam para os de Manaus, que as forneciam aos "patrões" dos rios caucheiros, que abasteciam seus subpatrões, que por sua vez as transferiam aos seus próprios subpatrões, concluindo-se o conjunto com adiantamentos em mercadorias feitos aos seringueiros. Esta cadeia toda estava fundada sobre o aviamento, o crédito e a dívida; salvo nas extremidades (isto é, os peixes pequenos das cabeceiras e os grandes de Belém e de Liverpool), cada qual era credor a montante e devedor a jusante. Nesse caso particular, a rede fractal recobria a fractalidade dos próprios rios, havendo um barracão, em cada foz ou boca de um afluente. A localização do barracão permitia identificar, então, de uma só vez, devedores e credores, o pequeno patrão da boca do M achadinho pegando suas mercadorias a crédito junto àquele que controlava a boca do Riozinho, e que se abastecia na boca do Tejo (Almeida 1992). Assim, nessa rede de que necessariamente só se percebia um fragmento, cada um tinha, em suma, uma apreensão legitimamente fundada sobre a idéia de que o todo era semelhante à parte, da qual se podia ter a experiência local. Contudo, a semel hança formal das duas redes, a antiga e aquela estabelecida no século XIX, faz-nos correr o risco de obliterar sua profunda diferença, a saber, aquela que separa um sistema igualitário de um sistema de dominação. Sob o antigo regime, todos os pontos de vista, ao mesmo tempo homólogos e independentes entre si, eram equivalentes: não havia ponto de vista privilegiado sobre o conjunto. Ao contrário, no caso do aviamen- 
to, estrutura de ordem, o crédito e a dívida eram transitivos: transmitiamse entre negociantes, patrões, subpatrões e seringueiros. De tal sorte que a jusante se tinha um ponto de vista relativamente "mais geral" sobre quem se achava a montante. Cada patrão ou subpatrão, por assim dizer, abraçava com o olhar o conjunto das ramificações e das capilaridades dos rios e afluentes até o menor igarapé que suas mercadorias atingiam, e que, em troca, o abasteciam de caucho. Sem deixar de ser particular, em cada foz de rio o ponto de vista tornava-se assim mais englobante. A generalidade do ponto de vista, embora este fosse formalmente equivalente a qualquer outro, aumentava assim de montante para jusante.

É isso, creio, o que explica o deslocamento da fonte dos poderes xamânicos ressaltado por Peter Gow (1996) e por Taussig (1987). Entre os Piro e os Campa do baixo Urubamba, mas também de modo geral em todo o ocidente amazônico, Gow (1996:96-97) observa o estatuto superior que gozam os xamãs das cidades (que no entanto invocam estágios na floresta sob a égide de xamãs indígenas) com relação aos seus confrades silvestres. Seguindo aqui os índios e os seringueiros, parece-me que seria preciso distinguir esferas de competência. Por exemplo, entre os Kaxi do J ordão, vários curandeiros continuam a atuar na aldeia sobre o que definem como seu domínio específico, à exclusão de tudo aquilo que recai (por vezes de modo ad hoc) sob a rubrica de doenças dos brancos. Com esse ajuste, a observação de Gow pode ser aplicada às bacias do J uruá e do Purus: em seu domínio de atuação, o jusante tem mais poderes xamânicos que o montante. Entre os Kaxinawá do Tarauacá, teme-se o poder dos Kulina a jusante; entre os Kaxinawá do Purus, o prestígio xamânico de Nito, um cariu, quer dizer, um Branco, cujos espíritos auxiliares são um xamã kulina falecido e o próprio Espírito Santo, conforme me relatou Cecilia McCallum. Parece, pois, que não é tanto a mestiçagem (à qual Gow atribui um estatuto "histórico" particular) que justifica o prestígio xamânico, mas a posição relativa na rede fluvial - metáfora de uma posição relativa quanto ao grau generalizador do ponto de vista particular¹. Em um código ao mesmo tempo genético e histórico (Gow 1991), a mestiçagem não seria, em suma, senão um avatar da mesma preocupação, a saber, a síntese da experiência local e do ponto de vista geral. Não se deve, com efeito, tomar o montante e o jusante ao pé da letra; trata-se apenas do código geográfico no qual se imprime um problema de ordem geral.

Esse problema da totalização dos pontos de vista locais, a "consonância dos pontos de vista singulares" 2, esta velha questão que Michel Serres (1968) e Gilles Deleuze (1988) redescobrem em Leibniz, encontra- 
se também sob uma outra forma. Em todo o ocidente amazônico, os xamãs, como se sabe, são os viajantes por excelência (ver, por exemplo, Chaumeil 1983). Sob o efeito do ayahuasca ou de outros alucinógenos, os xamãs viram tudo. É por isso que nada os surpreende. Viagens mais conformes à nossa definição usual acentuam seu prestígio, ou mesmo, ao menos em vários casos Pano, substituem uma aprendizagem de tipo tradicional. Crispim, um J aminaua do alto Bagé, durante decênios e até sua morte no começo dos anos 80 , foi o mais reputado xamã do alto J uruá, tanto junto aos índios como aos seringueiros. De sua vida, conta-se que, criado por um padrinho branco que o teria levado para o Ceará e, após um assassinato em que teria sujado as mãos, para Belém, onde teria estudado, ele teria voltado para o alto J uruá. Para Crispim, sua reputação xamânica explica-se por sua estada e seus estudos em dois lugares particularmente significativos: o Ceará (a cerca de quatro mil quilômetros dali), de onde provêm quase todos os seringueiros da região e onde desde então os Kaxinawá do Purus situam a raiz do céu (McCallum 1996a:61), e Belém, um dos últimos nós da rede do caucho. Não é, tampouco, indiferente que Crispim, voltando para os seus e estabelecendose na região como um xamã poderoso, tenha escol hido morar no lugar chamado Divisão, "partilha das águas", isto é, nas próprias cabeceiras de seis bacias fluviais distintas: as dos rios Humaitá, Liberdade, Gregório, Tarauacá, Dourado e Bagé. Assim, Crispim, um homem criado no extremo-jusante, estabelece-se em uma espécie de hipermontante: idealmente situado para encarnar a contento o projeto de junção do local e do global. É nesse sentido que Crispim é um tradutor.

Já se disse muitas vezes que os xamãs, viajantes no tempo e no espaço, são tradutores e profetas (p. ex., Kensinger 1995). Temos de nos entender quanto ao alcance dessa atribuição e não tomá-la como trivial. CabeIhes, sem dúvida, interpretar o inusitado, conferir ao inédito um lugar inteligível, uma inserção na ordem das coisas. Essa ordenação não se faz sem contestação e, freqüentemente, é objeto de ásperas disputas que se assentam tanto na política interna quanto nos sistemas de interpretação. Seria preciso ver nos guerrilheiros do MIR-Tupac A maru em 1965 o Inca reaparecido para destruir a ordem do poder? Coube aos xamãs Ashaninka debaterem e decidirem, sem que um consenso, aliás, jamais tenha sido estabelecido (Brown e Fernandez 1991).

Essa maneira de dar conta do processo, embora verdadeira, não o esgota e talvez passe ao largo de algo mais fundamental. Primeiro, porque se trata, de fato, de muito mais do que uma simples ordenação, e a tradução não é só uma tarefa de arrumação, de guardar o novo em velhas 
gavetas; trata-se de remanejamento mais do que de arrumação. Segundo, porque o xamã parece ser o contrário de um nomoteta. A o longo de suas viagens a outros mundos, ele observa sob todos os ângulos, examina minuciosamente e abstém-se cuidadosamente de nomear o que vê. Donde a suspensão da linguagem ordinária, substituída por essas “palavras torcidas", esse uso figurado e muito aproximativo dos cantos xamânicos yaminahua, tão bem descritos por Townsley (1993). Como se escrutasse por apal padelas, como se abordasse um domínio desconhecido cujos objetos só se deixam ver parcialmente, o xamã adota uma linguagem que expressa um ponto de vista parcial. Essas manchas claras são brânquias de peixes ou o colar de um caitetu? E o peixe acaba sendo chamado de caitetu. Há, sem dúvida aqui um jogo no qual a linguagem, em seu registro próprio, manifesta a incerteza da percepção alucinada. M as há, também, a tomada de consciência de uma relatividade, da "verdade da relatividade (e não a relatividade do verdadeiro)" (Deleuze 1988:30), pois nesses mundos ampliados só é possível ver sob perspectivas particulares. "Com palavras usuais, eu me esmagaria sobre as coisas - com palavras torcidas, rodeio-as e vejo-as claramente" (Townsley 1993:460).

Penso que aqui tocamos o âmago do problema. Com efeito, o que é uma tradução? Não é, dirá Benjamin, o que restitui fielmente os objetos designados, já que, afinal de contas, nas diferentes línguas todos os objetos fazem parte de conjuntos, de sistemas diferentes que expressam o que Benjamin chama de modos de intenção. Pão e brot significam ambos o mesmo objeto, mas diferem em seus modos de significação (intentio). A boa tradução é, então, aquela que é capaz de apreender os pontos de ressonância, de fazer com que a intentio em uma língua reverbere em outra. Mas se a coisa é possível, se é viável encontrar ecos de uma língua em outra, então existe a perspectiva (e para Benjamin, creio, a possibilidade real) de uma língua absoluta, a verdadeira linguagem. A tarefa do tradutor torna-se grandiosa, por ser ela a busca da verdadeira linguagem, da qual as línguas particulares seriam apenas fragmentos (Benjamin 1968:78), como os cacos de um vaso que, embora diferentes entre si, se ajustam perfeitamente para restituir um conjunto que os ultrapassa: o ajustamento dos cacos atesta a existência do vaso.

Há aqui uma ressonância - que não terá passado despercebida aos antropólogos - com o xamã da "Introdução à Obra de M arcel M auss" (Lévi-Strauss 1950), com a diferença que Lévi-Strauss, se acredita na pretensão, certamente não subscreve a realidade de uma língua adâmica. M as a transposição de contradições reais em diferentes códigos, como se, de tanto traduzi-las, fosse possível resolvê-las, a dolorosa sensibilidade 
do xamã às dificuldades e armadilhas dessas passagens entre códigos que jamais são inteiramente equivalentes, não é nisto que consiste o trabalho do tradutor?

A síntese original, o sistema sintagmático no qual há necessidade de aderência entre o som e o sentido, no qual o som e o sentido se ajustam sem fal has como o fruto e sua pele (Benjamin 1968), tudo isso se dissolveu. O que se trata de (re)construir é uma síntese original, uma nova maneira de pôr em relação níveis, códigos, pô-los em ressonância, em correspondência, de modo que esse mundo novo ganhe a consistência desejada para que se torne evidente (Taylor 1995). Em suma, que adquira um sentido, pois o sentido é, ao fim e ao cabo, a percepção de relações, uma "rede de associações que se referem umas às outras, semel hante a um dicionário ou a um banco de dados relacional" (Crick e Koch 1997:33). Quanto mais essas conexões se multiplicam, mais o sentido se enriquece: fórmulas da neurociência que lembram imediatamente a antiga questão do que, na análise estrutural dos mitos, significa "significar". O trabalho do xamã, sua esfera de competência, é essa tentativa de reconstrução do sentido, de estabelecer relações, de encontrar íntimas ligações. Não é, portanto, a coerência interna do discurso o que se procura, sua consistência advém antes do reforço mútuo dos planos em que se exprime, do habitus em suma.

Um exemplo: entre os Shipibo-Conibo (Gebhardt-Sayer 1986) grupos Pano ribeirinhos - , os textos dos cantos xamânicos obedecem a regras distintas das que regem as melodias. Amplamente improvisadas, as palavras descrevem um itinerário, balizam-no, traçam o sentido de seu percurso. Em contrapartida, as melodias, que formam um corpus que não de umas trinta unidades, são a tradução sonora de desenhos, de motivos pictóricos - os quene (ou kene) - que o dono do ayahuasca exibe ao xamã e que este transpõe simultaneamente para um código sonoro. Este código é decifrável, visto que pode ser retraduzido em uma forma visual. Conta-se (e pouco importa se a história é autêntica) que, antigamente, duas mulheres, sentadas de lados opostos de um grande vaso a ser decorado, eram capazes - sem se verem e unicamente guiadas pelos cantos xamânicos - de pintar os mesmos motivos e de fazê-los se juntarem nas extremidades (Gebhardt-Sayer 1986:210-211). A codificação sonora das visões e sua decifração permitem, assim, obter tanto desenhos imateriais, aplicados sobre os doentes a serem curados, quanto desenhos materializados sobre vasos, tecidos e corpos. Os aromas acrescentam um código olfativo aos precedentes, de tal modo que "os sons, as cores e os odores correspondem". 
“Os Ashaninka [explica Carlito Cataiano] consideram o japiim (Cacicus cela), que nós, Kaxi [i.e. Kaxinawá], chamamos txana, um curador poderoso. Os A shaninka gostam de fazer suas casas perto dos ninhos do txana, porque quando tomam cipó o espírito do txana vem ajudá-los a curar os doentes; em suas cantorias e mirações do cipó, os pajés A shaninka, em suas canções do ayahuasca chamam e vêem os espíritos do japiim e do japó; têm ainda muito respeito por esses dois pássaros, que fazem seus ninhos nas proximidades de suas casas; ninguém persegue esses pássaros, tidos como inteligentes, trabalhadores e, sobretudo, bons curadores [...]. Kaxi gosta de matar o chefe do japiim, aquele mais cantador, para usar na festa do Tirin ou então do Katxanawa; mata o chefe, tira o fato e as carnes e deixa só o couro, as penas, a cabeça e os pés; depois seca no sol ou na queitura do fogo, em cima do fogão; diz que é bom para abrir a memória dos cantadores de Katxanauá e Tirin; assim eles aprendem mais facilmente todas as canções de katxanawá e de Tirin e não se esquecem mais de cantá-las por inteiro [...]. Txana não é só o nome do japiim. Os Kaxi chamam também Txana aos cantadores das festas, da cantoria de cipó, mariri ou katxanawá, Tirin, Buna Kuin, Nixpupima e Hai Hai Ika" (Aquino e Cataiano no prelo).

Carlito é Kaxinawá. Vende picolé nas ruas de Rio Branco, capital do Acre, e vez por outra trabalha como assistente de antropólogos e de uma ONG. Mas é xamã também, misturando técnicas emprestadas dos Yawanaua e Katukina do Gregório e do Tarauacá, combinadas com rituais tomados da umbanda, aprendidos em Belém e Manaus. Sua clientela é formada por sua própria e grande família e por antigos seringueiros dos bairros mais pobres de Rio Branco. Nada disso nos surpreende mais. Tampouco nos surpreendem seu conhecimento das crenças xamânicas ashaninka e seu relativismo.

Com efeito, os A shaninka do alto J uruá têm uma consideração muito especial por toda a família dos japós. Em seu conjunto (que abarca a família I cteridae), os japós são chamados pelo nome genérico txowa, que designa também uma espécie particular, o Psarocolius sp. Todos os japós são humanos. Isto todo mundo percebe, já que eles vivem em sociedade, e tecem seus ninhos: são, em suma, tecelões como os A shaninka. Os xamãs que, sob o efeito do ayahuasca, sabem ver de forma adequada, comprovam essa condição humana dos japós: vivem ao modo dos homens, cultivam mandioca, bebem kamarãpi (ayahuasca), bebem cerveja de mandioca (caissuma). São inclusive superiores aos homens, na medida em que observam a paz interna e vivem sem discórdia. São os filhos que Pawa, o sol, deixou na terra, são os filhos do ayahuasca. Entre 
os japós, pássaros tecelões, o tsirotsi ou japiim (Cacicus cela) ocupa uma posição particular e suscita um interesse muito especial. Os tsirotsi vivem em bandos de uns trinta pássaros, particularmente associados, que tecem seus ninhos muito perto uns dos outros em uma mesma árvore. Escolhem a árvore por ela abrigar ninhos de certas vespas ou formigas cujas picadas são especialmente dolorosas. É esta, diz-se, a sua polícia, que os protege dos predadores, como o gambá, por exemplo. Os tsirotsi são pacíficos e só se tornam ferozes quando é o caso de defender os ovos brancos com pintas contra a cobiça dos tucanos e dos araçaris. O macho e a fêmea guardam os ovos juntos, mas só a fêmea trabalha, ao passo que o macho canta. Nada disso é muito excepcional entre os japós. O que, no entanto, distingue os japiim de todos os outros pássaros, é a capacidade que Ihes é atribuída de imitarem os chamados e os ruídos que escutam, sejam estes os cantos de outros pássaros, o tambor dos Ashaninka, o latido dos cães ou o choro das crianças (Pianko e Mendes no prelo).

Os xamãs têm uma associação muito especial com o tsirotsi, o japiim. Como Carlito afirma, este pássaro é um poderoso xamã. Os tsirotsi (ou tsiroti), segundo uma história recolhida junto a outros Ashaninka por Fernandez (1986:70 e ss.), são inclusive os descendentes de xamãs, que o personagem mítico Avireri, aquele que transformou alguns Ashaninka em animais, mudou, por distração, em pássaros. Esses xamãs - pai e filho - sabiam imitar todos os gritos de animais e eram, por conseguinte, grandes caçadores. $O$ filho casou-se com uma mulher de olhos azuis: todos os seus descendentes tinham olhos azuis também. Eis aqui explicitada a relação xamã-caçador, por intermédio do japiim. A particularidade de imitar os chamados de outros animais é posta a serviço da caça. Com efeito, é assim que procede o bom caçador: finge utilizar uma linguagem que não é a sua, uma linguagem de sedução, aquela por meio da qual os machos e as fêmeas se atraem. A relação da caça e da sedução é um tema tipicamente amazônico (ver, p. ex., Descola 1986), mas, aqui, esse tema se encarna em uma linguagem que não comunica, ou melhor, cuja única mensagem é o grito que atrai, que seduz. É um chamariz, uma isca. Um som sem sentido, um som com sentido único.

O japiim fala línguas que não são as suas, línguas estrangeiras que, nele, nada comunicam, exceto a sedução e a predação. Ele é uma ponte ilusória entre formas do ser. Corresponde, no mundo animal, àquela escada xamânica que liga mundos cortados entre si. É notável que na ausência do personagem japiim, utilizado para outros fins entre os grupos Pano da floresta, a mesma associação entre cantos xamânicos, mimetismo sonoro e caça esteja presente entre os yaminahua do Peru (Townsley 1993:454). 
A consciência do desmantelamento de uma ordem original e paradisíaca parece ser expressa por quase toda a Amazônia - e sobretudo entre os povos que decoram com motivos os tecidos, as cerâmicas e os cestos - na história da sucuri primordial, cujo corpo e cores variegadas estão na origem de todo o repertório de desenhos ${ }^{3}$. Despedaçada na cosmogonia do Vaupés, decomposta em desenhos discretos entre os Pano e os A ruaque, a sucuri parece o foco virtual de uma unidade perdida para sempre. Hoje em dia, é o múltiplo que reina: entre os Kaxi (Kensinger 1995; Lagrou 1996), almas dispersas no corpo, no olho, nos excrementos; saberes que se localizam nas mãos, no sexo, na pele, nas orel has (Kensinger 1995:237 e ss.; M cCallum 1996b:355 e ss.). Cada uma dessas instâncias tendo um ponto de vista diverso, é o corpo humano vivo que assegura, de modo transitório, o invólucro dessas perspectivas singulares.

Vimos que na prática xamânica opera um princípio semelhante, e isto não nos deve surpreender, dada a circularidade que opera na construção de esquemas conceituais. Para o xamã de um mundo novo, de pouca valia serão seus antigos instrumentos, as escadas xamânicas que Ihe dão acesso aos diversos planos cosmológicos (Weiss 1969; Chaumeil 1983), sua aprendizagem, seus espíritos auxiliares, suas técnicas; montagens de outras técnicas podem ser preferíveis. Mas, ainda assim, cabeIhe, "por dever de ofício", mais do que pelos instrumentos conceituais tradicionais, reunir em si mais de um ponto de vista. Pois, apenas ele, por definição, pode ver de diferentes modos, colocar-se em perspectiva, assumir o ol har de outrem (Viveiros de Castro 1996). E é por isso que, por vocação, desses mundos disjuntos e alternativos, incomensuráveis de algum modo, ele é o geógrafo, o decifrador, o tradutor.

Vê-se, portanto, que o "perspectivismo" amazônico que Eduardo Viveiros de Castro (1996) pôs em destaque em um artigo notável, e do qual extraiu várias implicações, se manifesta como um esquema em vários planos. Pois o problema geral do perspectivismo, aquele que Leibniz e Giordano Bruno descobriram, é justamente a questão da unidade, do invólucro, da convergência no sentido matemático, da série dos pontos de vista. Em suma, o problema da tradução. Não é sem dúvida fortuito que Leibniz e Benjamin adiantem uma solução semelhante: o que permite a totalização dos pontos de vista singulares e irredutíveis é a ressonância, a harmonia (Benjamin 1968:79, 81; Deleuze 1988:33). Na Amazônia, diríamos: é o xamã.

Dir-se-á: por que tantos esforços? M arshall Sahlins, que cito livremente aqui, ainda que com seu imprimatur, observou que um dos problemas da noção de globalização ou de sistema mundial é que este só é 
um sistema no sentido sintagmático, não, porém, no sentido paradigmático. Em outras palavras, talvez exista sistema, mas não existe cultura que Ihe corresponda (Sahlins 1988). Com efeito, malgrado a extraordinária difusão da mídia, não existe cultura global. Os paradigmas, as sínteses, as correspondências de sentido fazem-se em uma outra escala, de ordem mais local. M as como ter um ponto de vista local sobre um processo que nos ultrapassa, do qual não se controlam nem as causas nem os efeitos? De maneira fantasmática e à falta de outras instâncias, o controle se realiza pela conjunção, vista acima, entre o que é mais local e o que é mais global: Crispim, criado a jusante, se estabelece nas cabeceiras, na divisão das águas. O local mantém seus poderes, é até a fonte dos maiores poderes, e é nele que os xamãs urbanos irão prover-se. Mais uma vez, é seguindo os meandros de raciocínios aparentemente contraditórios que se pode esperar ultrapassar os paradoxos (Taylor 1995). Cabe, então, ao mais fraco, àquele que se acha o mais a montante na cadeia, ao colonizado, ao estrangeiro, efetuar uma tradução privilegiada: é por seu intermédio que o novo penetra o mundo (Bhabha 1994). Mas a inanidade da empresa permanece. Poder-se-ia ver nos esforços de tradução, de totalização, que evoquei, a tentativa, sempre votada ao fracasso, em qualquer escala que se a considere - e no entanto sempre recomeçada - de construir sentido.

Tradução de Tânia Stolze Lima Revisão da autora
Recebido em 20 de outubro de 1997

A provado em 15 de dezembro de 1997

M anuela Carneiro da Cunha é professora de antropologia da Universidade de Chicago. Foi professora da Universidade de São Paulo e da Universidade de Campinas. Entre seus livros figuram N egros, Estrangeiros - Os Escravos Libertos e sua Volta à África (1985); Os M ortos e os Outros (1978); Antropologia do Brasil: Mito, História e Etnicidade (1986); e Os Direitos do Í ndio (1987). 


\section{Notas}

1 Repare que, em alguns casos, essa associação do xamã com um jusante, sempre relativo, pode já estar dada mesmo antes do contato. Parece ser este o caso dos Matis (Erikson 1996:186).

2 É essa totalização do sistema, no seu aspecto comercial e na sua vertente interpretativa, que talvez dê conta da singularidade da cartografia dos Aruaques subandinos a que fizemos referência acima: os dois únicos lugares que não se replicam no espaço são precisamente os pontos de convergência dos xamãs e o ponto de origem de todo o comércio do sal.

3 Elsje Lagrou (1996:213, nota 18) além de estudá-la entre os Kaxinawá, recenseou a extraordinária difusão amazônica da associação da sucuri com os desenhos; ver Gow (1988:31), para os Piro; Gallois (1988), para os Waiãpi; Van Velthem (1984), para os Wayana-A paraí; Reichel-Dolmatoff (1978), para os Tukano; Roe (1989) e Illius (1987), para os Shipibo.

\section{Referências bibliográficas}

ALMEIDA, Mauro. 1992. Rubber Tappers of the Upper Jurua River, Brazil. The M aking of a Forest Peasant Economy. Ph.D. Dissertation, University of Cambridge.

AQUINO, Terri V. de e CATAIANO, Carlito. no prelo. "Aves Kaxinauá". In: M. Carneiro da Cunha e M. Almeida (orgs.), Enciclopédia da Floresta. O Alto J uruá.

BENJ AM IN, Walter. 1968. "The Task of the Translator". In: Illuminations. New York: Schoken Books. pp. 69-82.

BHABHA, Homi K. 1994. “How New- ness Enters the World: Postmodern Space, Postcolonial Times and the Trials of Cultural Translation". In: The Location of Culture. London: Routledge. pp. 212-235.

BLOCH, Maurice. 1992. Prey I nto Hunter: The Politics of Religious Experience. Cambridge: Cambridge University Press.

BROWN, Michael e FERNANDEZ, E. 1991. War of Shadows. The Struggle for Utopia in the Peruvian Amazon. Berkeley: University of California Press. 
CHAUMEIL, J ean-Pierre. 1983. Voir, Savoir, Pouvoir. Paris: École des Hautes Études en Sciences Sociales. CRICK, Francis e KOCH, Christof. 1997. “Why Neuroscience May Be Able to Explain Consciousness". Scientific A merican Special Issue: Mysteries of the Mind.

DELEUZE, Gilles. 1988. Le Pli. Leibniz et le Baroque. Paris: Les Éditions de Minuit.

DESCOLA, Philippe. 1986. La Nature Domestique. Symbolisme et Praxis dans L'Écologie des Achuar. Paris: Éditions de la Maison des Sciences de l'Homme.

ERIKSON, Philippe. 1993. “Une Nébuleuse Compacte: Le Macro-Ensemble Pano". L'Homme, 126-128:45-58. . 1996. La Griffe des Aieux. Marquage du Corps et Démarquages Ethniques chez les Matis d'Amazonie. Paris: Éditions Peeters.

FERNANDEZ, Eduardo. 1986. “EI Pensamiento Ashaninca y los Recursos Naturales". A nthropológica, 4:6989.

GALLOIS, Dominique. 1988. O Movimento na Cosmologia Waiãpi: Criação, Expansão e Transformação no Universo. Tese de Doutorado, USP.

GEBHARDT-SAYER, Angelika. 1986. “Una Terapia Estética. Los Diseños Visionarios del Ayahuasca entre los Shipibo-Conibo". A mérica Indígena, XLVI(1):189-218.

GOW, Peter. 1988. “Visual Compulsion. Design and Image in Western Amazonian Cultures". Revindi, 2:19-32. .1991. Of Mixed Blood: Kinship and History in Peruvian Amazonia. Oxford: Clarendon Press. . 1996. “River People Shamanism and History in Western Amazonia". In: N. Thomas e C. Humphrey (eds.), Shamanism, History and the State. Ann Arbor: Michigan University Press.

GRUZINSKI, Serge. 1988. La Colonisation de I'I maginaire. Sociétés Indigènes et Occidentalisation dans le M exique Espagnol. Paris: Gallimard. HUGH-J ONES, Stephen. 1996. “Shamans, Prophets, Priests and Pastors". In: N. Thomas e C. Humphrey (eds.), Shamanism, History and the State. Ann Arbor: Michigan University Press. pp.32-75.

ILLIUS, Bruno. 1987. A ni Shinan: Shamanismus bei den Shipibo-Conibo. Tübingen: Verlag S\&F.

KENSINGER, Kenneth. 1995. How Real People Ought to Live. Prospect Heights: Waveland Press.

LAGROU, Elsje. 1996. “Xamanismo e Representação entre os Kaxinawá". In: E. J . Langdon (org.), N ovas Perspectivas sobre Xamanismo no Brasil. Florianópolis: Ed. da UFSC. pp. 197-231.

LÉVI-STRAUSS, Claude. 1950. “Introduction à l'Oeuvre de Marcel Mauss". In: M. Mauss - Sociologie et A nthropologie. Paris: Presses Universitaires de France. pp. IX-LII.

MCCALLUM, Cecilia. 1996a. “M orte e Pessoa entre os Kaxinawá". Mana, 2(2):49-84.

. 1996b. "The Body that Knows: From Cashinahua Epistemology to a Medical Anthropology of Lowland South America". Medical Anthropology Quarterly, 10(34):347372.

PIANKO, Moises e MENDES, M argarete. no prelo. "Aves entre os A shanin- 
ka". In: M. Carneiro da Cunha e M. Almeida (orgs.), Enciclopédia da Floresta. O Alto J uruá.

REICHEL-DOLMATOFF, Gerardo. 1978.

Beyond the Milky Way: Hallucinatory I magery of the Tukano Indians. Los Angeles: Regents UC.

RENARD-CASEVITZ, France-M arie. 1992. “História Kampa, M emória Ashaninka". In: M. Carneiro da Cunha (ed.), História dos Índios no Brasil. São Paulo: Companhia das Letras/ FAPESP/SM C. pp. 197- 212. . 1993. "Guerriers du Sel, Sauniers de la Paix". L'Homme, XXXIII (24):25-43.

ROE, PETER G. 1989. "Of Rainbow, Dragons and the Origins of Designs". Latin A merican Indian Literature J ournal, 5(1):1-67.

SAHLINS, Marshall. 1988. "Cosmologies of Capitalism: The Trans-Pacific Sector of the World System". Proceedings of the British Academy, 74:1-51.

SERRES, M ichel. 1968. Le Système de Leibniz. Paris: PUF.

TAUSSIG, Michael. 1987. Shamanism, Colonialism and the Wild Man. A Study in Terror and Healing. Chicago: Chicago University Press.

TAYLOR, A nne-Christine. 1995. “The Soul's Body and its States: An Amazonian Perspective on the Nature of Being Human". J ournal of the Royal Anthropological Institute (N.S.), 2:201-215.

TOWNSLEY, Graham. 1993. "Song Paths. The Ways and Means of Shamanic Knowledge". L'Homme, XXXIII (24):449-468.

TURNER, Terence. 1988. “Ethno-ethnohistory: Myth and History in Native
South American Representations of Contact with Western Society". In: J. Hill e R. Wright (eds.), Rethinking $\mathrm{H}$ istory and $\mathrm{M}$ yth. Indigenous South American Perspectives on the Past. Urbana: University of IIIinois Press. pp. 235-281.

VAINFAS, Ronaldo. 1995. Santidade. São Paulo, Companhia das Letras.

VAN VElthem, Lúcia H. 1984. A Pele de Tuluperê: Estudos dos Trançados dos Índios Wayana-Apalai. Dissertação de Mestrado, USP.

VERNANT, J ean-Pierre. 1982. "La Belle M ort et le Cadavre Outragé". In: G. Gnioli e J.-P. Vernant (eds.), La Mort, les Morts dans les Sociétés Anciennes. Paris/Cambridge: Maison des Sciences de I'Homme/ Cambridge University Press. pp. 45-76.

VIVEIROS DE CASTRO, Eduardo. 1996. “Os Pronomes Cosmológicos e o Perspectivismo Ameríndio". M ana, (2)2:115-144.

WEISS, Gerald. 1969. The Cosmology of the Campa Indians of Eastern Peru. Ph.D. Dissertation, University of Michigan.

WRIGHT, Robin e HILL, J onathan. 1992. "Venancio Kamiko. Wakuénai Shaman and Messiah". In: E. J. Langdon e G. Baer (eds.), Portals of Power. pp. 257-286. 
Resumo

O que é o trabalho xamânico na Amazônia de hoje? Como se pode entender, de forma mais geral, o florescimento do xamanismo e a extensão de sua clientela em situações de dominação colonial, desde pelo menos o século XVI? Que hierarquia de poderes e competências xamânicas e que formas específicas correspondem aos diferentes sistemas políticos e aos diversos nexos entre o local e o global? Por dever de ofício, cabe ao xamã o trabalho de tradução. Sugere-se que tradução deva ser entendida aqui em um sentido forte, benjaminiano, de procura de ressonâncias e reverberações entre sistemas e códigos diversos, e de totalização de pontos de vista parciais.

\section{Abstract}

What is the shaman's labor in the Amazon today? M ore generally, how should one account for the expansion of shamanism and its clientele in colonial situations since the sixteenth century? Which shamanic power hierarchies and competences and which specific forms correspond to different political systems and to each kind of nexus between the local and the global? The shaman is, by his very trade, a translator. It is suggested here that translation should be understood in its strong, Benjaminian sense, as a search for resonances and reverberations between different codes and systems, and as a totalization of partial perspectives. 